\title{
Heuristic Glance at the \\ Fundamentals of General Psychology
}

Movsesyan Arsen A., engineer-physicist,

independent researcher, plars7@ mail.ru

In the article are offered the models allowing deeper understand the essence of the concepts "will" and "attention", and to determine their possible types, which allows us to clear up the essence of the concept "faith". Proceeding from the principle of symmetry of the Laws of Nature and of some general physical representations, a heuristic glance at the fundamentals of General Psychology is proposed, which allows us to discern interrelations between the basic concepts of General Psychology, and thereby systematizing them. In doing so the author does not attempt to reduce complex psychical processes to mechanical schemes, and at all not concerned these processes, but the real unity of the foundation of science as a whole concerning to the General Psychology is trying to show.

Keywords: A Will; An Attention; Phase State; Phase Transition; Spectrum

\section{Introduction}

The main purpose of this article is to present a new look at the fundamentals of General Psychology. In due to certain circumstances, life has forced me to take up the study of the foundations of General Psychology. Having a technical background, I'm used to the fact that this or that "exact" science in its foundations proceeds from some general principles, from which other important assertions of system are output, and thereby the unity of system manifests. But in the case of General Psychology I had not observed anything like it. The basic psychical concepts and categories are as though scattered, and their interrelations are confused. Most of all I liked the book of Maklakov A.G. "General Psychology" [1], but and here I did not find that slimness and beauty which are manifested in the commonality of the basic principles and concepts one or another cognitive system. Therefore the idea arose to detect the interrelation between the concepts of General Psychology, in the availability of which I no doubted, because knew that the symmetry of the Laws of Nature relatively to its different objects exists.

This article is of an interdisciplinary nature. The epoch of differentiation of the scientific knowledge has ended; the epoch of synthesis of the scientific knowledge has come. But this does not mean that the methods of one scientific discipline can be directly applied to study another scientific discipline. For example, B. Spinoza in his work "Ethics Demonstrated in Geometrical Order" on the basis of axioms, lemmas and theorems tries to prove some propositions of Ontology and Psychology, and J. Guilford in his 120th factorial model of intellect as a basis takes methods of Mathematical Statistics. As many psychologists rightfully point out, it is impossible to reduce complex psychical processes to mechanical schemes. Yes, indeed, it is so, but the application of some general physical and mathematical representations in General Psychology as not a basic, but an auxiliary tool can prove to be very useful. And it will be demonstrably shown in the article. Let's not forget that although there are many scientific disciplines, but science's foundation is a united one.

So, as the physical level in part of the substance consists of four main phase states (solid body, liquid, gas, plasma), and in doing so a defined mechanism to convert the substance from one phase state to another exists, likewise all structures of a human (physical, psychical, informational and unifying levels), the characteristics of which and there are the concepts of General Psychology, consist of four main phase states with the relevant mechanisms of phase transitions. In this, in particular, the symmetry of the Laws of Nature manifests.

At first the concepts of "will" and "attention" will be considered, which are important in analysis of interrelation of some human's structures, and in doing so geometric concepts will be used, but not for the purpose of explaining the psychical processes, only for determining the kinds of will and attention. Further, a new look at the fundamentals of General Psychology will be presented, proceeding from some general physical representations. And in the end the brief conclusions will be made.

\section{Briefly About the Concepts "Will" and "Attention"}

The concepts of "will" and "attention" are important not only for the General Psychology, but also for the Theory of Cognition in general. A will there is the ability to active or passive action, which can be directed outward with a view of committing an action or directed inwards with a view of refraining from committing certain action. We will distinguish the will of mind (M) and the will of reason (R). The will 
of reason is related with the implementation of the spiritual installations of human, and the will of mind is related to the satisfaction of the sensual needs of human. Both wills can be active (A) and passive $(P)$, may wear voluntary $(\mathrm{V})$ and forced $(\mathrm{F})$ character. Also we will distinguish the mixed will, the selfforced will and the multidirectional will as a manifestation of the indicated pairs of will in their unity, respectively. As a model for determining the kinds of will we will use the geometric concept - octahedron. If above indicated three pairs of will be perceive as the three diagonals of octahedron, abbreviated $-\mathrm{R} \leftrightarrow \mathrm{M}$, $\mathrm{A} \leftrightarrow \mathrm{P}, \mathrm{V} \leftrightarrow \mathrm{F}$ respectively, then we receive the Conditional Octahedron of Will, shown in Fig. 1, which will help us deeper understand the essence of the concept "will".

We will conduct an analysis of the Octahedron of Will to determine the kinds of will. It is seen, that one or two vertices not form the kind of will, but three vertices belonging to one facet form the kind of will. The Octahedron of Will has eight facets, each of which forms the kind of will. Three or four vertices, which cannot form a facet, do not form the kind of will. Any two facets, which have a common edge, also form the kind of will. Since the Octahedron of Will has the twelve edges, then we have the twelve more kinds of will. Any two facets having a common vertex without common edges, and also any three or four facets having a common vertex form a Regular Quadrangular Pyramid of Will. Such pyramids in the Octahedron of Will are six, and hence, we have the six more kinds of will. Any two opposite facets, any three or four facets having no common vertex and also any five or more facets of the Octahedron of Will are constitute the whole Octahedron of Will, thus forming the one more kind of will. Thus, we have

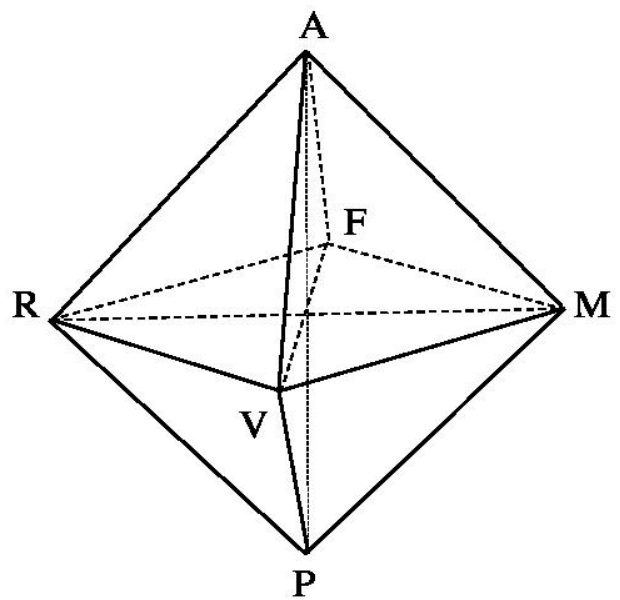

Fig. 1

Conditional Octahedron of Will $\mathrm{N}=8+12+6+1=27$ kinds of will. The obtained result is a consequence of visual-imaginative representations. However, the same result is possible to obtain combinatorially. Since we have three groups, in each of which are the three genus of will, then the number of possible samplings is equals to $\mathrm{N}=3^{3}=27$. Appropriate kinds of will are represented with the help of Table 1 .

Table 1. The Kinds of Will

\begin{tabular}{|l|l|l|l|}
\hline № & $\begin{array}{l}\text { Conditional } \\
\text { designations }\end{array}$ & Part of the Octahedron of Will & \\
\hline 1 & RVA & Facet & The kinds of will \\
\hline 2 & RFA & Facet & Voluntarily-active will of reason \\
\hline 3 & RVP & Facet & Forcibly-active will of reason \\
\hline 4 & RFP & Facet & Forcibly-passive will of reason \\
\hline 5 & MVA & Facet & Voluntarily-active will of mind \\
\hline 6 & MFA & Facet & Voluntarily-passive will of mind \\
\hline 7 & MVP & Facet & Forcibly-active will of mind \\
\hline 8 & MFP & Facet & Forcibly-passive will of mind \\
\hline 9 & RVP+RVA & Facets with a common edge RV & Active self-forced will of reason \\
\hline 10 & RAF+RFP & Facets with a common edge RF & Passive self-forced will of reason \\
\hline 11 & RVA+RAF & Facets with a common edge RA & Voluntary multidirectional will of reason \\
\hline 12 & RFP+RVP & Facets with a common edge RP & Forced multidirectional will of reason \\
\hline 13 & MVP+MVA & Facets with a common edge MV & Active self-forced will of mind \\
\hline 14 & MAF+MFP & Facets with a common edge MF & Passive self-forced will of mind \\
\hline 15 & MVA+MAF & Facets with a common edge MA & Voluntary multidirectional will of mind \\
\hline 16 & MFP+MVP & Facets with a common edge MP & Forced multidirectional will of mind \\
\hline 17 & RVA+MVA & Facets with a common edge RM & Voluntarily-active mixed will \\
\hline 18 & RAF+MAF & Facets with a common edge AF & Voluntarily-passive mixed will \\
\hline 19 & RVP+MVP & Facets with a common edge VP & Forcibly-active mixed will \\
\hline 20 & RFP+MFP & Facets with a common edge FP & Forcibly-passive mixed will \\
\hline 21 & RVAFP & Pyramid of the will of reason & Multidirectional self-forced will of reason \\
\hline 22 & MVAFP & Pyramid of the will of mind & Multidirectional self-forced will of mind \\
\hline 23 & AVMFR & Pyramid of voluntary will & Multidirectional mixed voluntary will \\
\hline 24 & PVMFR & Pyramid of forced will & Multidirectional mixed forced will \\
\hline 25 & VRAMP & Pyramid of active will & Mixed self-forced active will \\
\hline 26 & FRAMP & Pyramid of passive will & Mixed self-forced passive will \\
\hline 27 & RVMFAP & Octahedron of Will & Mixed self-forced multidirectional will \\
\hline
\end{tabular}


Further let's try to sort out with the kinds of attention. How without the necessary physical force there is no movement of the physical body, exactly the same without the sufficient attention there are no "movements" of the consciousness and thought. This means that attention there is the force of the mind and the reason, or in other words, psychical and informational forces respectively. Therefore it is necessary to distinguish the attention of mind, that is, psychical force, and the attention of reason, that is, the informational force. As a model for determining the kinds of attention one can use geometric concept "cube". Two types of attention can be apportion by the following genera: voluntary (V) and forced (F), sustainable (S) and diffused (D), external (E) and internal (I), concentrated (C) and distributed (Db), as well as willed, variable, multidirectional and polycentric as a manifestation of the indicated pairs of attention in their unity, respectively. If the indicated four pairs of attention will be perceived as the four diagonals of cube, in abbreviated form as $-\mathrm{V} \leftrightarrow \mathrm{F}, \mathrm{S} \leftrightarrow \mathrm{D}, \mathrm{E} \leftrightarrow \mathrm{I}, \mathrm{C} \leftrightarrow \mathrm{Db}$ respectively, then we shall obtain the Conditional Cube of Attention shown in Fig. 2, which will help us deeper understand the essence of the concept "attention". A little analysis of the Cube of Attention will allow to determine the kinds of attention.

Each of six facets of the Cube of Attention forms the kind of attention. Any two facets having a common edge form the kind of attention: since the Cube of Attention has the twelve edges, then we obtain the twelve more kinds of attention. Any three facets with a common vertex form the kind of attention: since the Cube of Attention has the eight vertices, then we have the eight more kinds of attention. Any facet together with one of four other vertices form the kind of attention, consequently, we have yet twenty four kinds of attention. Any facet together with a diagonal of opposite facet form the kind of attention, consequently, we obtain yet twelve kinds of attention. Three edges, which emanate from one vertex, form the kind of attention, that is, we get the eight more kinds of attention. Three edges and the diagonal of cube, which emanate from one vertex, form the kind of attention that gives us the eight more kinds of attention. If consistently connect the ends of the interbreeding diagonals of opposite facets

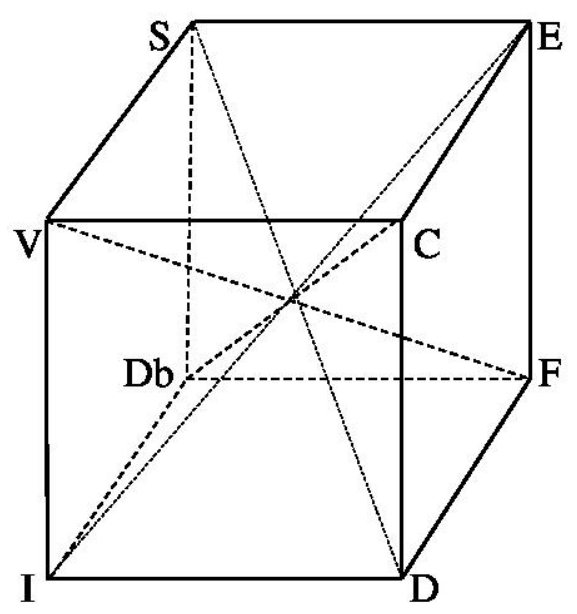

Fig. 2 then we get a tetrahedron. In cube can be inscribe two different tetrahedrons, and therefore we have the two more kinds of attention. And finally, the whole cube forms the one kind of attention. The summation of obtained numbers will determine the total number of the kinds of attention: $N=6+12+8+24+12+8+8+2+1=81$. The same result is possible to obtain combinatorially. Since we have four groups in each of which are three genus of attention, then the number of possible samplings is equals to $\mathrm{N}=3^{4}=81$. We will not list the kinds of attention.

\section{Briefly About the New Look at the Fundamentals of General Psychology}

There are at least four levels of cognition: 1. physical; 2. psychical; 3. informational; 4. Absolute. The first three levels will be considered on the example of a human, who most fully contains in himself these levels. Each of this levels is consists of three sublevels. So, the physical level of human consists of the following three sublevels: matter, adaptation, physiokinetics.

Matter is the substance of which the ambient world and a human himself consist. The basic phase states are solid bodies, liquid, gases, plasma (transitional form is an amorphous body). The structural unit of phase states is atom, molecule. The basis of structural unit is elementary particles. The characteristic of mobility of the structural unit is the temperature. The mechanism of phase transitions is the change in temperature by means of heating or cooling. The source of temperature change is heat. The essence of heat is electromagnetic waves, that is, the photon flux. Depending on the photon energy we can distinguish the following classes of electromagnetic waves that form Spectrum: 1. Radio waves; 2. The infrared radiation; 3 . The visible light (red, orange, yellow, green, blue, indigo, violet, which in the aggregate form white light); 4 . The ultraviolet radiation; 5 . The $\mathrm{x}$-ray radiation; 6 . The gamma radiation.

When heating the substance an interaction of atoms with the quanta of electromagnetic field occurs, whereby the atoms, grasping thermal photons, are excited, that is, the intensity of their motion increases, which leads to an increase in temperature, and thus the transition of substance from one phase state to another occurs. Approximately the same happens with other levels. 
Adaptation is a mechanism that provides the vital activity of human in conditions of changing internal and external factors of habitat. The basic phase states are equilibrium, steadiness, unsteadiness, crisis (transitional form is a chronic state). The structural unit of phase states is the ligament of "impact reaction", or differently, the mapping, which is the process of converting the energy of the irritant of mechanical, thermal, electromagnetic or other character into electrical signals of receptor. The basis of structural unit is elementary particles. The characteristic of mobility of the structural unit is the disbalance between impact and response reaction of organism. The mechanism of phase transitions is the change of disbalance by means of the disorder or restore of equilibrium parameters of the internal or external environment. The source of disbalance change is the susceptibility of organism. The essence of susceptibility is sensations, that is, the signal flux. Since the signal has electromagnetic nature, then its main characteristic is conductivity. Depending on the conductivity of signal we have the following Spectrum of Sensations: 1. Subsensory; 2. Subthreshold; 3. Sensory (gustatory, tactile, organic, olfactory, vestibular, auditory, visual); 4. Superthreshold; 5. Synaesthesical; 6. Extrasensory.

At disorder equilibrium parameters of the internal or external environment, the interaction of organism with the flux of those or other signals occurs, which by means of the mapping are converted to the human's sensations, and the higher the susceptibility of organism, the more distinctly a human feels the disbalance of equilibrium parameters. When a certain limit reaching, the phase transition of adaptation occurs from equilibrium state through steadiness and unsteadiness to crisis.

Hardly more detailed I will tell about the concept of "adaptation". In modern Psychology there is an opinion that adaptation it is a property of living organisms to adjust to external conditions. But it seems to me that this is not entirely accurate, since adaptation it is not a property, but a certain mechanism, i.e. a structure in charge for interaction with the external environment. For example, the expansion of metals when heating is the property of metals, which is conditioned by the presence at them of the crystal structure as a form of the realization of principle of the minimum of free energy, that is, the property of the expansion of metals is consequence of the presence of crystal structure. Similarly, the adaptation of the living organisms to external conditions is consequence of the presence of the mechanism of adaptation, that is, the words "adaptation" and "adjustment" are not synonyms, and even more so, Adaptation is not a property, but a mechanism that ensures adjustment. The process of heating a solid body, the final result of which is an increase of the internal energy of body, up to phase changes, occurs thanks to the presence of the mechanism of interaction of the quanta of electromagnetic field with the atoms of substance. Similarly, the process of disorder of the equilibrium state of living organism, the final result of which is the change of its internal parameters with a view to adjust to changed external conditions, occurs thanks to the presence of the mechanism of perception by the body of external signals through appropriate sensations. This mechanism of perception and there is the mechanism of adaptation.

Physiokinetics is a totality of physiological mechanisms of human's motions in the process of its vital functions such as respiration, circulation of the blood, metabolic processes, etc. The basic phase states are sleep, relaxation, wakefulness, stress (transitional form is a fatigue). The structural unit of phase states is an impulse of motion, i.e. the motion of material objects. The basis of structural unit is elementary particles. The characteristic of mobility of the structural unit is the reactivity of organism. The mechanism of phase transitions is the change of reactivity by means of the excitation or inhibition of nervous system. The source of reactivity change is the impact from external or internal factors. The essence of impact is a cause of motion, that is, the flux of the various processes of motion. Depending on object of motion one can distinguish the following classes of the processes of motion which form Spectrum: 1. Motion of ions; 2. Motion of gases; 3. Motion of liquids (water, sols, suspensions, gels, pastes, emulsions, gas emulsions); 4. Motorics; 5. Ontogeny; 6. "Motion" into the future (reproduction).

The cause of any motion is impact, without which the motion is impossible. In doing so the impact is manageable factor. There is external impact, the control source of whose is not important for us in this matter, there is internal impact outgoing from various human's organs and structures, and there is yet the impact outgoing from the nervous system of human, which is a visible center of the control by our motions. Speaking about impulse of motion as the structural unit of the phase states of Physiokinetics is meant namely the impulse outgoing from the nervous system of human. Even if there are no both external and internal impacts, there is some minimum impulse of motion outgoing from the nervous system which ensures the functioning of body, such as in the state of deep sleep. Thus, it comes about the interaction of the impulses of motion from the nervous system with external and internal impacts. The mechanism of transition of the Physiokinetics from one phase state to another and back again is the change of the reactivity of human's organism by means of excitation or inhibition of the nervous system because of 
gain or easing impacts from external or internal factors. For example, under the action of serotonin which produced in the central part of midbrain the inhibition of nervous system occurs, and hence the decline of the reactivity of organism occurs, that leads to the state of sleep. After sleeping a human some time is located in the state of relaxation, at which a gradual increase of the reactivity of organism and the predominance processes of excitation of the nervous system over inhibition are occur, that leads to a transition into the state of wakefulness, which is characterized by the high electrical activity of brain, and hence by the high reactivity of organism. Because of the gain of impacting factors, the reactivity of organism may rise before a certain maximum acceptable level, in resulting of which the state of stress comes.

All said above about the phase states, characteristics and spectra of physical level can be represented by using Tables 2, 3 and 4 .

Table 2. The Phase States of the

Physical Level of Human

\begin{tabular}{|c|l|l|l|}
\hline \multicolumn{4}{|c|}{ Sublevels of the physical level of human } \\
\hline Phase states & \multicolumn{1}{|c|}{ Matter } & \multicolumn{1}{c|}{ Adaptation } & Physiokinetics \\
\hline 1 & Solid bodies & Equilibrium & Sleep \\
\hline 2 & Liquid & Steadiness & Relaxation \\
\hline 3 & Gases & Unsteadiness & Wakefulness \\
\hline 4 & Plasma & Crisis & Stress \\
\hline
\end{tabular}

Table 3. Phase Characteristics of the Physical Level of Human

\begin{tabular}{|l|l|l|l|l|}
\hline \multirow{2}{*}{$№$} & \multirow{2}{*}{$\begin{array}{l}\text { Characteristics of phase states } \\
\text { and transitional processes }\end{array}$} & \multicolumn{1}{|c|}{ Matter } & \multicolumn{1}{|c|}{ Adaptation } & \multicolumn{1}{|c|}{ Physiokinetics } \\
\cline { 3 - 5 } 1 & $\begin{array}{l}\text { The basis of the structural } \\
\text { unit of phase states }\end{array}$ & Elementary particle & Elementary particle & Elementary particle \\
\hline 2 & $\begin{array}{l}\text { The structural unit } \\
\text { of phase states }\end{array}$ & Atom, molecule & Mapping & Impulse of motion \\
\hline 3 & $\begin{array}{l}\text { The characteristic of } \\
\text { the mobility of structural units }\end{array}$ & The temperature & Disbalance & Reactivity \\
\hline 4 & $\begin{array}{l}\text { The process of increasing } \\
\text { the mobility of structural units }\end{array}$ & Heating & Disorder & Excitation \\
\hline 5 & $\begin{array}{l}\text { The process of decreasing } \\
\text { the mobility of structural units }\end{array}$ & Cooling & Restore & Inhibition \\
\hline 6 & $\begin{array}{l}\text { The source of } \\
\text { the process of mobility }\end{array}$ & Heat & Susceptibility & Impact \\
\hline 7 & $\begin{array}{l}\text { The essence of } \\
\text { the source of process }\end{array}$ & $\begin{array}{l}\text { Electromagnetic } \\
\text { wave }\end{array}$ & Sensations & Cause of motion \\
\hline 8 & Quantum of the essence of source & Photon & Signal & Process \\
\hline
\end{tabular}

Table 4. The Spectra of Electromagnetic Waves, Sensations and Causes of Motion

\begin{tabular}{|c|c|c|c|}
\hline \multicolumn{4}{|c|}{ Spectrum } \\
\hline № & $\begin{array}{c}\text { Electromagnetic waves } \\
\text { (photon flux) }\end{array}$ & $\begin{array}{l}\text { Sensations } \\
\text { (signal flux) }\end{array}$ & $\begin{array}{l}\text { Cause of motion } \\
\text { (flux of processes) }\end{array}$ \\
\hline 1 & Radio waves & Subsensory & Motion of ions \\
\hline 2 & The infrared radiation & Subthreshold & Motion of gases \\
\hline 3 & The visible light & Sensory & Motion of liquids \\
\hline 3.1 & red & gustatory & water \\
\hline 3.2 & orange & tactile & sols \\
\hline 3.3 & yellow & organic & suspensions \\
\hline 3.4 & green & olfactory & gels \\
\hline 3.5 & blue & vestibular & pastes \\
\hline 3.6 & indigo & auditory & emulsions \\
\hline 3.7 & violet & visual & gas emulsions \\
\hline 4 & The ultraviolet radiation & Superthreshold & Motorics \\
\hline 5 & The $\mathrm{x}$-ray radiation & Synaesthesical & Ontogeny \\
\hline 6 & The gamma radiation & Extrasensory & "Motion" into the future \\
\hline
\end{tabular}


The psychical level of human consists of the following three sublevels: reprimagination, the mind, the will of mind. The word "reprimagination" is new, therefore requires the necessary clarification. Typically, remembering, storage and reproduction called in one word - memory, but this is not true. As a figurative comparison, we will accept "archive" as a prototype of the concept "memory". In order to extract some necessary information from the archive, a human must have read, listen or preview a certain massif of information stored in the archive, and only after proper analysis he will choose the necessary information. That is, the mechanism of extraction is different from other mechanisms having relation to memory, which is denoted in using the word "reproduction", but since the extraction of knowledge and information from the storage have actually is a $\underline{\boldsymbol{r e}}$-creation of one or another primary images, which are converted into secondary images, it would be logical to call this process "reprimagination".

Reprimagination is a mechanism of conscious re-creation of the secondary images which are recorded in the neural memory. The basic phase states are forgetting, anamnesis, recognition, recollection (transitional form is a reminder). The structural unit of phase states is information recording in the neural memory. The basis of structural unit is consciousness. The characteristic of mobility of the structural unit is the veracity of restored information. The mechanism of phase transitions is the change in the veracity by the reconstructing or distortions of information. The source of change of the veracity is re-created ties. The essence of re-created ties is the result of interconnection of the two processes: 1 . The re-creation of neural ties, that is, the flux of neurons; 2. The re-creation of associative ties, that is, the flux of ties. The first relates to biochemical processes which occur in the neural circuits, and the second is related to the circumstance that reality itself and various events are perceived by us in a complex, i.e. are interrelated as with the external environment so and with our internal state. Depending on the objective significancy of tie, we can distinguish the following classes of associative ties that form the Spectrum: 1. Spatial-coordinate situation; 2. Temporal situation; 3. The internal state (sensations, desires, evaluations, emotions, feelings, words, thoughts); 4. External background situation; 5. External substantive situation; 6 . The biological situation.

By the reconstruction of secondary images a conscious search for appropriate neuronal and associative ties relatively this or other information occurs, and the more ties are re-created, the above the veracity of restored information. In doing so it possible the distortion of information due to the loss, changes or generalization of some details of the re-created image, since with the passage of time, for various reasons, the erosion of neural traces can occur. Previously memorized information can be forgotten, or although happens hard-to-reach, but a human by himself come to anamnesis after applying of necessary efforts, or becomes recognizable at the time of re-perception, or is recollected without hindrance. There are cases when information is memorized securely, but for whatever reasons turns out is temporarily blocked.

The mind is a mechanism allowing a person to knowingly operate with various objects of reality, giving them titles with the use of words, which are representing themselves as the unit notion or the general notion. The basic phase states are notion, judgment, inference, theory (transitional form is $a$ definition). The structural unit of phase states is knowledge recorded in the neural memory. The basis of structural unit is consciousness. The characteristic of mobility of the structural unit is the degree of awareness. The mechanism of phase transitions is the change in the degree of awareness by means of thinking or unthinking. The source of change of the degree of awareness is reasoning. The essence of reasoning is the search of justified ties, that is, the flux of logic ties. About the spectrum of justified ties we will talk a little later, when will be mentioned the reason.

During thinking the degree of awareness of the meaning of one or another notion, as a knowledge recorded in the neural memory, increases as a result of justified reasoning, and on the basis of this notion becomes possible to build some judgment. A further increase in the degree of awareness along the same scheme allows to go from the judgment to the inference, and then to a certain theory.

The will of mind is a decision-making mechanism at the level of consciousness with the purpose to meet the sensual needs of human. The basic phase states are need, inclination, desire, passion (transitional form is an intention). The structural unit of phase states is the aspiration of mind, since the will of mind, in essence, is a manifestation of the conscious "I" of human, which is always to strive for something. The basis of structural unit is consciousness. The characteristic of mobility of the structural unit is the awareness of need. The mechanism of phase transitions is the change of the awareness of need by means of concentration or dispersal the attention of mind. The source of change of the awareness of need is motivation. The essence of motivation is the decision-making in the process of constructing logically interrelated arguments. Depending on the liberty of decision-making we have the following Spectrum of Decision-making: 1. Negative voluntary - N-decision; 2. Negative voluntary, but after 
overcoming doubts - ND-decision; 3. The decision-making does not depend on the free will of an individual - NFW-decision (negatively forced - NF-decision, negatively forcible - NFb-decision, a negative decision after the voluntary transfer of one's will - NV-decision, positive forcible - PFb-decision, positive forced - PF-decision, a positive decision after the voluntary transfer of one's will - PV-decision, the lack of a decision after the voluntary transfer of one's will - L-decision); 4. Uncertainty - U-decision; 5. Positive voluntary, but after overcoming doubts - PD-decision; 6. Positive voluntary - P-decision.

Since the need of human is a totality of the aspirations of his mind, then at the concentration of the attention of mind upon one or another need, the search of justified decisions to meet the given need begins, at which the aspirations of mind under the influence of motivated arguments escalates, that is, the awareness of need of this need increases, that to encourages a human to commit certain actions, and thus the transition of the need of human via his inclination and desire to passion occurs.

All said above about the phase states, characteristics and spectra of psychical level can be represented by using Tables 5, 6 and 7 .

Table 5. The Phase States of the Psychical Level of Human

\begin{tabular}{|c|l|l|l|}
\hline \multicolumn{4}{|c|}{ Sublevels of the psychical level of human (psych) } \\
\hline Phase states & Reprimagination & The mind & The will of mind \\
\hline 1 & Forgetting & Notion & Need \\
\hline 2 & Anamnesis & Judgment & Inclination \\
\hline 3 & Recognition & Inference & Desire \\
\hline 4 & Recollection & Theory & Passion \\
\hline
\end{tabular}

Table 6. Phase Characteristics of the

Psychical Level of Human

\begin{tabular}{|l|l|l|l|l|}
\hline \multirow{2}{*}{$№$} & \multicolumn{2}{|c|}{$\begin{array}{c}\text { Characteristics of phase states } \\
\text { and transitional processes }\end{array}$} & \multicolumn{2}{c|}{ Sublevels of the psychical level of human (psych) } \\
\cline { 3 - 5 } 1 & $\begin{array}{l}\text { The basis of the structural unit } \\
\text { of phase states }\end{array}$ & Consciousness & Consciousness & Consciousness \\
\hline 2 & The structural unit of phase states & Information & Knowledge & $\begin{array}{l}\text { The aspiration } \\
\text { of mind }\end{array}$ \\
\hline 3 & $\begin{array}{l}\text { The characteristic of } \\
\text { the mobility of structural units }\end{array}$ & Veracity & $\begin{array}{l}\text { The degree of } \\
\text { awareness }\end{array}$ & $\begin{array}{l}\text { The awareness } \\
\text { of need }\end{array}$ \\
\hline 4 & $\begin{array}{l}\text { The process of increasing } \\
\text { the mobility of structural units }\end{array}$ & Reconstruction & Thinking & $\begin{array}{l}\text { Concentration of the } \\
\text { attention of mind }\end{array}$ \\
\hline 5 & $\begin{array}{l}\text { The process of decreasing } \\
\text { the mobility of structural units }\end{array}$ & Distortion & Unthinking & $\begin{array}{l}\text { Dispersal of the } \\
\text { attention of mind }\end{array}$ \\
\hline 6 & The source of the process of mobility & Recreating ties & Reasoning & Motivation \\
\hline 7 & $\begin{array}{l}\text { The essence of } \\
\text { the source of process }\end{array}$ & $\begin{array}{l}\text { 1. Neural circuits } \\
\text { 2. Associative ties }\end{array}$ & Justification & Decision-making \\
\hline 8 & Quantum of the essence of source & Ties & Logic ties & Argument \\
\hline
\end{tabular}

Table 7. The Spectra of Associative Ties and Decision-making

\begin{tabular}{|c|l|l|}
\hline \multicolumn{3}{|c|}{ Spectrum } \\
\hline \multirow{2}{*}{1} & \multicolumn{1}{|c|}{$\begin{array}{c}\text { Associative ties } \\
\text { (flux of ties) }\end{array}$} & $\begin{array}{c}\text { Decision-making } \\
\text { (flux of arguments) }\end{array}$ \\
\hline 2 & Spatial-coordinate situation & N-decision \\
\hline 3 & Temporal situation & ND-decision \\
\cline { 2 - 3 } 3.1 & The internal state & NFW-decision \\
\cline { 2 - 3 } 3.2 & desires & NF-decision \\
3.3 & evaluations & NFb-decision \\
\hline 3.4 & emotions & NV-decision \\
3.5 & feelings & PFb-decision \\
3.6 & words & PF-decision \\
3.7 & thoughts & PV-decision \\
\hline 4 & External background situation & U-decision \\
\hline 5 & External substantive situation & PD-decision \\
\hline 6 & The biological situation & P-decision \\
\hline
\end{tabular}


The informational level of human consists of the following three sublevels: imagination, the reason, the will of reason.

Imagination is a mechanism of creative creating of new images in the representation of thought. The basic phase states are recombination, introduction, substitution, creation (transitional form is $a$ transfiguration). The structural unit of phase states is representation. The basis of structural unit is thought. The characteristic of mobility of the structural unit is the degree of novelty of the image. The mechanism of phase transitions is the change in the degree of novelty by means of the formation or disbandment of images. The source of change of the degree of novelty is the transformation of images. The essence of transformation is the consideration, that is, the flux of images (thought-forms), co-located in unity. Depending on the degree of awareness we can distinguish the following classes of considerations which form Spectrum: 1. Secondary; 2. Re-creative; 3. Creative (reincarnation, material, sound, light, verbal, informational, figurative); 4. Inspiration; 5. Dream; 6. Slumber.

When forming imaginary images, creative combination of the flux of images in the presentation of thought occurs, and if in doing so recombination of the elements of some initial image occurs, then the degree of novelty of this image is increases. The phase transition occurs under such transformation, when a new element is introduced into the original image. A further increase in the degree of novelty is associated not simply with the introduction of a new element, but with substitution of old elements. Full substitution provides the phase transition to the state of creation a new image.

The reason is a mechanism that enables a person to mentally handle with various objects of reality, displaying them in physical reality by means of images with the use of signs. The basic phase states are sign, symbol, meaning, idea (transitional form is an allegory). The structural unit of phase states is information. The basis of structural unit is thought. The characteristic of mobility of the structural unit is the degree of comprehension. The mechanism of phase transitions is the change of the degree of comprehension by means of reflection or thoughtlessness. The source of change of the degree of comprehension is shrewdness. The essence of shrewdness is mindsight, that is, the flux of discretion ties. The word "mindsight" is formed by combination of two words - mind and sight, and as a result we obtain an important word, which literally means "the eyes of mind". Then educated from this word adjective and verb will sound as follows: mindsightive and mindsightize, respectively. Three possible manifestations of the justification of mind (visual, explanatory, logical) and three possible manifestations of the mindsight of reason (figurative, contemplative, insightful) form a united Spectrum of Understanding, which provides interrelation of psychical and informational levels, what in its turn stipulates a holistic perception of reality. Depending on the depth of penetration of the tie we have the following Spectrum of Understanding: 1. Visual; 2. Explanatory; 3. Logical (distinction, comparison, analogy, excretion, generalization, analysis, synthesis); 4. Figurative; 5. Contemplative; 6. Insightful.

Understanding at the level of mind indicates the ability of a human to the justifications, i.e. to skill to find justified ties, and the understanding at the level of reason there is the ability to the mindsight, i.e. to skill to mindsightize ties. Thus, the understanding is more than knowledge and information, as very often a person knows about those or other ties, or heard about them, but not understand them. Reflection by means of shrewdness relatively of one or another sign image allows revealing the internal and external ties of this image, thereby increasing the amount of information regarding given sign what leads to an increase in the degree of comprehension. At the certain degree of understanding the phase transition from sign to symbol occurs, and then to meaning. Further reflections lead to the nucleation of some idea outgoing of given sign.

The will of reason is a mechanism of orientation in the aspirations and hopes of human when implementing his spiritual installations. The basic phase states are installation, opinion, belief, faith (transitional form is a worldview). The structural unit of phase states is the argument in respect of the issues: "Do I act correctly?" and "What is my purpose?". The basis of structural unit is thought. The characteristic of mobility of the structural unit is the assessment of correctness, briefly - assessment. The mechanism of phase transitions is the change of assessment by means of concentration or dispersal the attention of reason. The source of change of the assessment is goal-setting. The essence of goal-setting is dual, on the one hand, it is the aspiration of spiritual gaze of a human, and on the other hand, it is the source on to which the gaze of human is directed as a landmark, that is, the trust. Depending on the directivity of the gaze of human, bearing in mind his spiritual aspirations, we have the following Spectrum of Aspirations: 1. Pecuniary; 2. Soulful; 3. Social (individual, family, genus, nation, country, Earth, the Universe); 4. Cognitive; 5. Spiritual and moral; 6. Absolute. Depending on the landmark, at which the spiritual gaze of human in the evaluation of the correctness of his thoughts, aspirations and actions is aimed, 
we have the following Spectrum of Trust: 1. On a case; 2. On the personal experience; 3. On an individual consciousness (scheme, plan, theoretical calculation, project, model, awareness, comprehension); 4. On the help; 5. On prediction. 6. On God. Prediction can bear different character - from encouraging loved ones to Biblical prophecy. As for God, each person perceives Him in their own way: for someone God is nature, higher intelligence, etc., but there are those for whom God is the One Whom Christ called His Father.

Since the spiritual installation of human there is the aggregate of the arguments of his reason, then at the concentration of the attention of reason on one or another spiritual installation the search of mindsightive orientation for the implementation of this installation begins, at which the arguments of reason under the influence of purposeful spiritual aspirations (gazes) are being strengthened, that is, the assessment of the correctness of this installation is increased, that gives a person more confidence in the commission of certain actions, and in result, the transition of the installation of human through his opinion and belief to faith occurs.

All said above about the phase states, characteristics and spectra of informational level of a human, his spirit, can be represented by using Tables 8,9 and 10 .

Table 8. The Phase States of the

Informational Level of Human

\begin{tabular}{|c|l|l|l|}
\hline \multicolumn{3}{|c|}{ Sublevels of informational level of a human } \\
\hline \multirow{2}{*}{ Phase states } & \multicolumn{2}{|c|}{ Informational structure (the spirit) } \\
\cline { 2 - 4 } & Imagination & The reason & The will of reason \\
\hline 1 & Recombination & Sign & Installation \\
\hline 2 & Introduction & Symbol & Opinion \\
\hline 3 & Substitution & Meaning & Belief \\
\hline 4 & Creation & Idea & Faith \\
\hline \multicolumn{4}{|c}{} \\
\hline
\end{tabular}

Table 9. Phase Characteristics of the Informational Level of Human

\begin{tabular}{|l|l|l|l|l|}
\hline \multirow{2}{*}{ No } & \multirow{2}{*}{$\begin{array}{c}\text { Characteristics of phase states } \\
\text { and transitional processes }\end{array}$} & \multicolumn{3}{|c|}{ Sublevels of informational level of a human } \\
\cline { 3 - 5 } & \multicolumn{1}{|c|}{$\begin{array}{c}\text { Tmagination } \\
\text { The basis of the structural unit } \\
\text { of phase states }\end{array}$} & Thought & Thought & The will of reason \\
\hline 2 & The structural unit of phase states & Representation & Information & Argument \\
\hline 3 & $\begin{array}{l}\text { The characteristic of } \\
\text { the mobility of structural units }\end{array}$ & $\begin{array}{l}\text { The degree } \\
\text { of novelty }\end{array}$ & $\begin{array}{l}\text { The degree of } \\
\text { comprehension }\end{array}$ & $\begin{array}{l}\text { The assessment } \\
\text { of correctness }\end{array}$ \\
\hline 4 & $\begin{array}{l}\text { The process of increasing } \\
\text { the mobility of structural units }\end{array}$ & Formation & Reflection & $\begin{array}{l}\text { Concentration of the } \\
\text { attention of reason }\end{array}$ \\
\hline 5 & $\begin{array}{l}\text { The process of decreasing } \\
\text { the mobility of structural units }\end{array}$ & Disbandment & Thoughtlessness & $\begin{array}{l}\text { Dispersal of the } \\
\text { attention of reason }\end{array}$ \\
\hline 6 & The source of the process of mobility & Transformation & Shrewdness & Goal-setting \\
\hline 7 & $\begin{array}{l}\text { The essence of } \\
\text { the source of process }\end{array}$ & Consideration & $\begin{array}{l}\text { Discretion ties } \\
\text { (mindsight) }\end{array}$ & $\begin{array}{l}\text { 1. The aspiration of reason } \\
\text { 2. Trust }\end{array}$ \\
\hline 8 & Quantum of the essence of source & Thought-form & Ties & Aspiration (gaze) \\
\hline
\end{tabular}

Table 10. The Spectra of Consideration,

Understanding, Aspiration and Trust

\begin{tabular}{|c|c|c|c|c|}
\hline \multicolumn{5}{|c|}{ Spectrum } \\
\hline № & $\begin{array}{c}\text { Consideration } \\
\text { (flux of thought-forms) }\end{array}$ & $\begin{array}{l}\text { Understanding } \\
\text { (flux of ties) }\end{array}$ & $\begin{array}{c}\text { Aspiration } \\
\text { (flux of aspirations) }\end{array}$ & $\begin{array}{c}\text { Trust } \\
\text { (flux of gazes) }\end{array}$ \\
\hline 1 & Secondary & Visual & Pecuniary & On a case \\
\hline 2 & Re-creative & Explanatory & Soulful & On the personal experience \\
\hline 3 & Creative & Logical & Social & On an individual consciousness \\
\hline 3.1 & reincarnation & distinction & individual & scheme \\
\hline 3.2 & material & comparison & family & plan \\
\hline 3.3 & sound & analogy & genus & theoretical calculation \\
\hline 3.4 & light & excretion & nation & project \\
\hline 3.5 & verbal & generalization & country & model \\
\hline 3.6 & informational & analysis & Earth & awareness \\
\hline 3.7 & figurative & synthesis & The Universe & comprehension \\
\hline 4 & Inspiration & Figurative & Cognitive & On the help \\
\hline 5 & Dream & Contemplative & Spiritual and moral & On prediction \\
\hline 6 & Slumber & Insightful & Absolute & On God \\
\hline
\end{tabular}


Each of the three above mentioned levels consists of the three sublevels. In order the nine sublevels could concertedly interface, unifying structures are needed, which only three: the neural memory, the overall structure, the soul.

Neural memory is a unifying structure that provides the connection between the physical and psychical levels of human through fixation and storage information by means of neurochemical processes. The basic phase states are loss, traces, part, preservation (transitional form is a blocking). The structural unit of phase states is information. The basis of structural unit is the signals of perception. The characteristic of mobility of the structural unit is the accessibility of information. The mechanism of phase transitions is the change of availability through reliable neural record or the erasure of neural traces. The source of changes of the accessibility is the consolidation of neural traces. The essence of consolidated neural traces is ordered neural circuits, i.e. the groupings of neurons which are formed under the influence of electromagnetic pulses through biochemical reactions. The activity of neural circuit depends on the number of neurons of this circuit. Depending on the number of neurons we can distinguish the following classes of neuron circuits that form the Spectrum: 1. The pair of neurons; 2. The nodal group of neurons; 3. The neural network (linear-nodal, single-level, plano-nodal, hierarchical, linear-hierarchical, multi-level, plano-hierarchical); 4. The peripheral nervous system; 5. The central nervous system; 6 . The nervous system.

Reliable fixation of neural traces by consolidating of relevant neural circuits increases the accessibility toward information fixed in the neural memory of human. In this the essence of the mechanism of phase transitions of the neural memory is consists. The first three classes of neural circuits are schematically shown in Fig. 3.

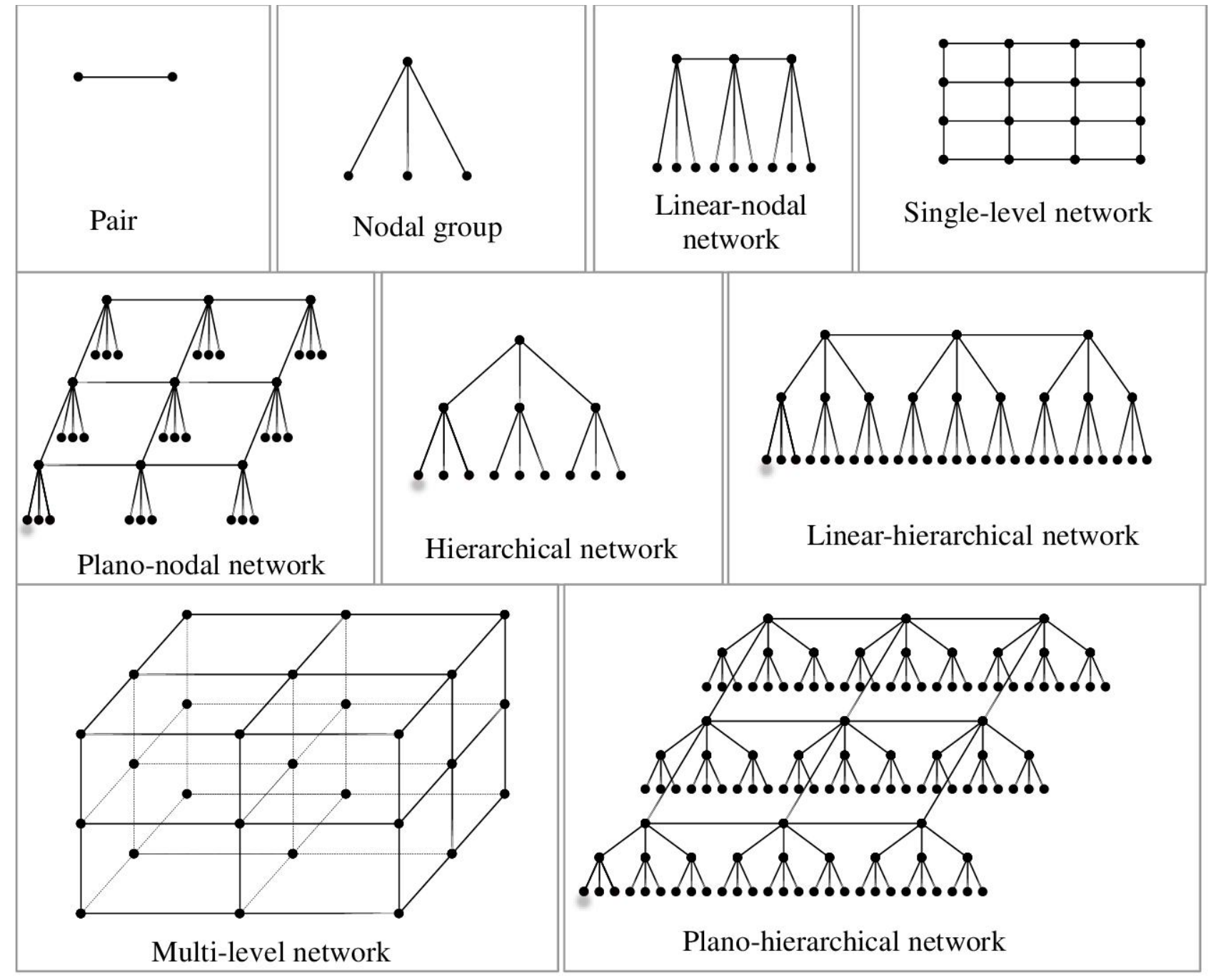

Fig.3. The Classes of Neuron Circuits 
Reliable neural record actually means the reliability of remembering and preservation of information, the probability of which increases if some event occurs in the following conditions: of heightened emotional background; of heightened concentration of attention; manifestations of willed self-control; meaningful perception of memorized information; of preliminary goal-setting on memorizing; learning, i.e. the multiple repetition of memorized material; application of other special techniques. If all of it no, then over time, the stored information can be lost, or away from it may stay some traces or parts as a result of erasure of the neural traces.

The overall structure is a unifying structure that provides the connection between the physical, psychical and informational levels of human, thereby allowing eliciting and developing initially nested personal qualities and abilities. The basic phase states are individual, individuality, personality, righteous man (transitional form is a doer). The structural unit of phase states is self-consciousness. The basis of structural unit is the concept of "I". The characteristic of mobility of the structural unit is the internal freedom of human. The mechanism of phase transitions is the change of internal freedom through the development or degradation of a human. The source of changes of the internal freedom is the capabilities that initially are nested in the form of makings. The essence of capabilities is the personal qualities that can be detected by means of labor. Depending on the I-states (I-biological, I-physical, I-skilful, I-social, I-moral, I-spiritual) and the difficulties of manifestation we have the following classes of personal qualities and abilities that form the Spectrum: 1. Biological; 2. Physical; 3. Abilities (practical, intellectual, organizational, analytical, creative, humanitarian, strategic); 4. Social; 5. Moral; 6. Spiritual.

The human is an individual, initially possessing exclusively characteristic only to him biophysical, psychological and spiritual properties. The becoming of human by means of the development of capabilities given to him in the form of makings, which are disclosed with the help of labour in the form of care by relatives in childhood, parenting and training in the youthful period, self-learning and self-improvement in adulthood, promotes to the increase of the self-awareness of individual under the influence of acquired personal qualities and abilities, that increase his internal freedom, and as a result an individual becomes at first an individuality, then a personality, and finally, a righteous man as the manifestation of "plasmic" state of the overall structure of human.

Soul is a unifying structure that provides the interconnection of spirit and psyche with the physical body and the outside world. The basic phase states are tranquility, anxiousness, exaltation, affect (transitional form is a mood). The structural unit of phase states is internal process. The basis of structural unit is the unity of the movement of thought, consciousness and elementary particles, briefly - outburst. The characteristic of mobility of the structural unit is the degree of composure. The mechanism of phase transitions is the change of the degree of composure through the unrestraint or restraint. The source of changes of the degree of composure is experiences. The essence of experiences is the emotions, that is, the flux of reflections of the internal processes in the outside world. Depending on the source of formation is possible to distinguish the following classes of emotions that form the Spectrum: 1. The emotions of sensation; 2. The emotions of experiences; 3 . The emotions of assessment (extremely negative, negative, not categorical, indeterminacy, shortcoming, positive, excellent); 4. The emotions of solution; 5. The emotions of self-sensation; 6 . The emotions of expectation.

The restraint and unrestraint are associated with the will of reason: a human with a strong will is restrained and a human with a weak will is unrestrained. The amplification of restraint through of suppressing emotional experiences promotes to ordering of the internal processes, and thereby a human provides the tranquility of soul. If, on the contrary, the amplification of unrestraint occur, then the internal processes in the form of emotional outbursts are break outward, and thus the phase transition of soul into the state of anxiousness occur, and then into the state of exaltation. At extreme forms of unrestraint is observed a state of affect.

All said above about the phase states, characteristics and spectra of the unifying structures of human can be represented by using Tables 11,12 and 13 .

Table 11. The Phase States of the

Unifying Structures of Human

Unifying Structures of Human
\begin{tabular}{|c|l|l|l|}
\hline \multicolumn{3}{|c|}{ Sublevels of the unifying structures of human } \\
\hline Phase states & Neural memory & The overall structure & \multicolumn{1}{|c|}{ Soul } \\
\hline 1 & Loss & Individual & Tranquility \\
\hline 2 & Traces & Individuality & Anxiousness \\
\hline 3 & Part & Personality & Exaltation \\
\hline 4 & Preservation & Righteous man & Affect \\
\hline
\end{tabular}


Table 12. Phase Characteristics of the

Unifying Structures of Human

\begin{tabular}{|l|l|l|l|l|}
\hline \multirow{2}{*}{ № } & $\begin{array}{l}\text { Characteristics of phase states and } \\
\text { transitional processes }\end{array}$ & \multicolumn{2}{|c|}{ Sublevels of the unifying structures of human } \\
\cline { 3 - 5 } 1 & $\begin{array}{l}\text { The basis of the structural unit } \\
\text { of phase states }\end{array}$ & Signals & "I" & Outburst \\
\hline 2 & $\begin{array}{l}\text { The structural unit } \\
\text { of phase states }\end{array}$ & Information & Self-consciousness & Internal process \\
\hline 3 & $\begin{array}{l}\text { The characteristic of } \\
\text { the mobility of structural units }\end{array}$ & Accessibility & Internal freedom & $\begin{array}{l}\text { The degree of } \\
\text { composure }\end{array}$ \\
\hline 4 & $\begin{array}{l}\text { The process of increasing } \\
\text { the mobility of structural units }\end{array}$ & $\begin{array}{l}\text { Reliable } \\
\text { neural record }\end{array}$ & Development & Unrestraint \\
\hline 5 & $\begin{array}{l}\text { The process of decreasing } \\
\text { the mobility of structural units }\end{array}$ & $\begin{array}{l}\text { Erasure or } \\
\text { blocking }\end{array}$ & Degradation & Restraint \\
\hline 6 & $\begin{array}{l}\text { The source of } \\
\text { the process of mobility }\end{array}$ & $\begin{array}{l}\text { Consolidation } \\
\text { of neural traces }\end{array}$ & The capabilities & Experiences \\
\hline 7 & $\begin{array}{l}\text { The essence of } \\
\text { the source of process }\end{array}$ & Neural circuits & $\begin{array}{l}\text { The personal } \\
\text { qualities }\end{array}$ & Emotions \\
\hline 8 & Quantum of the essence of source & Neuron & Quality & Reflection \\
\hline
\end{tabular}

Table 13. The Spectra of the

Unifying Structures of Human

\begin{tabular}{|c|c|c|c|}
\hline \multicolumn{4}{|c|}{ Spectrum } \\
\hline № & $\begin{array}{l}\text { Neuron circuits } \\
\text { (flux of neurons) }\end{array}$ & $\begin{array}{l}\text { Personal qualities } \\
\text { (flux of qualities) }\end{array}$ & $\begin{array}{c}\text { Emotions } \\
\text { (flux of reflections) }\end{array}$ \\
\hline 1 & Pair of neurons & Biological & Emotions of sensation \\
\hline 2 & Nodal group of neurons & Physical & Emotions of experiences \\
\hline 3 & The neural network & Abilities & Emotions of assessment \\
\hline 3.1 & linear-nodal & practical & extremely negative \\
\hline 3.2 & single-level & intellectual & negative \\
\hline 3.3 & plano-nodal & organizational & not categorical \\
\hline 3.4 & hierarchical & analytical & indeterminacy \\
\hline 3.5 & linear-hierarchical & creative & shortcoming \\
\hline 3.6 & multi-level & humanitarian & positive \\
\hline 3.7 & plano-hierarchical & strategic & excellent \\
\hline 4 & The peripheral nervous system & Social & Emotions of solution \\
\hline 5 & The central nervous system & Moral & Emotions of self-sensation \\
\hline 6 & Nervous system & Spiritual & Emotions of expectation \\
\hline
\end{tabular}

Thus, a human consists at least of three structures on each of the three levels - physical, psychical and informational, united by means of the three unifying structures. Total - twelve.

\section{Brief Conclusions}

1. Science shall not only go deep into the cognitive process, but also have to expand, that is, the differentiation of scientific disciplines must be accompanied by an interdisciplinary synthesis. In the case of interdisciplinary synthesis can achieve significant results if properly used initially given the symmetry of the Laws of Nature;

2. As shown above, the concepts "will" and "attention" not simply important concepts of General Psychology, but they are complex two-level concepts, and always need to distinguish the will of mind and the will of reason, and also the attention of mind and the attention of reason. Such representation of the concept "will" allows to define another complex concept by form: faith is the fourth ("plasmic") state of the will of reason.

3. Representation of the twelve sublevels of human as the interaction of structural units of their phase states with the quanta of corresponding spectra allows us to introduce into the foundation of General Psychology slimness and beauty which emanate from the symmetry of the Laws of Nature. And it allows us in a new way look at well-known concepts of General Psychology, which in turn opens up wide possibilities for carrying the analysis of various psychological processes. For example, practically all dictionaries by Psychology and Philosophy are asserting that the thinking is the supreme cognitive psychical process. In fact it is not so, because of itself the thinking is the process devoid of content. In 
order to heat up a metal, it is necessary deliver to him the heat, the essence of which is electromagnetic wave, that is, a flux of photons; therefore the heating is the process devoid of content, since it is impossible to heat up anything without a source of heat. Here more important the energy of photons, i.e. need to talk about the headship of the interaction of matter with the quanta of electromagnetic field. The thinking is an analog of heat, and therefore cannot be the main, but here more important the reasoning, the essence of which is the detection of justified ties, that is, necessary to speak about some psychical interaction which occurs through the reasoning.

4. Represented new look on the basics of General Psychology allows us to understand the relationship of the mind, the reason, the will of mind and the will of reason with the Spectrum of Understanding. Just as the source of energy for the atoms is thermal photons, the source of energy for the aspirations of mind and the arguments of reason are the arguments of mind and the aspirations of reason, respectively. If then take into account that the arguments of reason as the structural units of phase states of the will of reason are associated with the arguments of mind as the quanta of conscious decision-making process through the Spectrum of Understanding, we obtain the following Remarkable Ligament: the aspirations of reason $\rightarrow$ the arguments of reason $\leftrightarrow$ The Spectrum of Understanding $\leftrightarrow$ the arguments of mind $\rightarrow$ the aspirations of mind. The submitted ligament shows that the aspirations of reason are prioritized relative to the aspirations of mind, or otherwise, spiritual is more than psychical. It is high time for Modern Psychology to take up the serious scientific development such important concepts as "soul" and "spirit". 5. A proper understanding of the fundamental bases of General Psychology is the "key" for resolve many important issues in the socio- and anthrop-directed scientific disciplines.

\section{References}

1. Maklakov A.G. Obshchaya psihologiya. SPb.: Piter, 2008.

(Maklakov A.G. General Psychology. SPb.: Peter, 2008).

2. Movsesyan A.A. Glavnoye Prednaznacheniye Zemlyan. Razvilka: Plars-M, 2013 (2 izd.)

(Movsesyan A. A. The Main Predestination of Earthlings. Razvilka: Plars-M, 2013 (2 ed.)).

01.02.2015 C Arsen A. Movsesyan

This research received no specific grant from any funding agency 